\title{
ENTRE SÍMBOLOS, MISTÉRIOS E A CURA: PLANTAS MÍSTICAS DOS QUINTAIS DE UMA COMUNIDADE RURAL PIAUIENSE
}

\author{
Paulo Henrique da Silva ${ }^{*}$, Ykaro Richard Oliveira², Maria Carolina De Abreu ${ }^{3}$
}

\author{
${ }^{1}$ Graduado em Ciências Biológicas, Universidade Federal do Piaui, Rua Cícero Eduardo, s/n, Bairro Junco, CEP: 64600-000, Picos-PI, Brasil. ORCID: \\ 0000-0003-2027-4925 \\ ${ }^{2}$ Mestrando do Programa de Pós-graduação em Botânica, Universidade Estadual de Feira de Santana, Av. Transnordestina, s/n, Bairro Novo Horizonte, \\ CEP: 44036-900, Feira de Santana - BA, Brasil. ORCID: 0000-0002-9382-5583 \\ ${ }^{3}$ Docente Adjunto II do Departamento de Ciências Biológicas, Universidade Federal do Piauí, Rua Cícero Eduardo, s/n, Bairro Junco, CEP: 64600-000, \\ Picos-PI, Brasil. ORCID: 0000-0001-8206-7273 \\ *Autor para correspondência: paulohenriquemb1@gmail.com
}

Recebido em 08 de março de 2017. Aceito em 25 de fevereiro de 2018. Publicado em 06 de abril de 2018.

Resumo - O ser humano sempre dependeu dos vegetais para a sua sobrevivência, desde necessidades basais até simbólicas, procurando na natureza as soluções para os males que o afligia. Nesse sentido, o objetivo desse estudo foi levantar as plantas de uso místico cultivadas nos quintais da comunidade rural Aroeiras, Monsenhor Hipólito-PI, bem como suas indicações terapêuticas. Para isso, os dados foram coletados através de excursões que incluíram entrevistas semiestruturadas e turnêsguiadas pelos quintais, os quais foram selecionados por amostragem "bola de neve". Ao todo, 71 quintais foram averiguados e em $85,91 \%$ destes havia algum tipo de vegetal cultivado com indicação mística. Logo, a pesquisa possibilitou registrar 12 espécies místicas pertencentes a 8 famílias botânicas, sendo a família Cactaceae a mais expressiva, com 5 diferentes espécies. As plantas mais encontradas nos quintais foram: Jatropha gossypiifolia, Melocactus zehntneri, Sansevieria trifasciata var. laurentii, Cereus jamacaru e Ruta graveolens. Portanto, pode-se constar que, dentro da miscelânea de usos dos recursos naturais, a cura para o corpo e para o espírito por meio do uso de plantas se mostrou notória na comunidade, fazendo-se necessário o registro e a valorização desta prática, essencial à conservação e manutenção da diversidade biológica e cultural.

Palavras-chave: Comunidade Aroeiras; Conhecimento Tradicional; Etnobotânica; Plantas Mágicas.

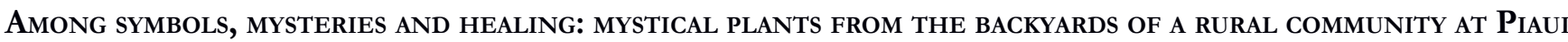

ABstract - Human beings have always depended on plants for their survival, from basic to symbolic needs, seeking in nature the solutions to the evils that afflicted them. Therefore, the objective of this study was to evaluate the mystic use of plants grown in the backyards of the rural community of Aroeiras, Monsenhor Hipolito-PI, as well as their therapeutic indications. For this, the data were collected on excursions that included semi-structured interviews and guided tours in the backyards, which were selected by "snowball" sampling. In total, 71 quintals were investigated and in $85.91 \%$ of them some kind of plants with mystical indication was cultivated. Therefore, the research made it possible to register 12 mystical species belonging to 8 botanical families, with Cactaceae family being the most expressive with 5 different species. The most frequently encountered mystical plants in the gardens were: Jatropha gossypiifolia, Melocactus zehntneri, Sansevieria trifasciata var. laurentii, Cereus jamacaru and Ruta graveolens. Accordingly, it can be stated that, within the miscellany of uses of natural resources, the use of plants as a cure for the body and for the spirit was shown to be notorious in the community, making it necessary to register and value this practice, essential for the conservation and maintenance of biological and cultural diversity.

Keywords: Aroeiras Community; Traditional Knowledge; Ethnobotany; Magical Plants. 


\section{Entre símbolos, misterios y la cura: plantas místicas de los Jardines de una comunidad RURAL en Piauí}

RESUmen - El hombre siempre dependió de los vegetales para su supervivencia, desde necesidades basales hasta simbólicas, buscando en la naturaleza las soluciones para los males que lo afligían. En ese sentido, el objetivo de este estudio fue hacer un levantamiento de las plantas de uso místico cultivadas en los jardines de la comunidad rural Aroeiras, Monsenhor Hipolito-PI, así como sus indicaciones terapéuticas. Para eso, los datos fueron recogidos a través de excursiones que incluyeron entrevistas semiestructuradas y visitas guiadas por los jardines, los cuales se seleccionaron por muestreo "bola de nieve". En total, 71 jardines fueron investigados y en el 85,91\% de estos había algún tipo de vegetal cultivado con indicación mística. Consecuentemente, la investigación posibilitó registrar 12 especies místicas pertenecientes a 8 familias botánicas, siendo la familia Cactaceae la más significativa, con 5 especies diferentes. Las plantas más encontradas en los jardines fueron: Jatropha gossypiifolia, Melocbactus zehntneri, Sansevieria trifasciata var. laurentii, Cereus jamacaru y Ruta graveolens. Por lo tanto, se puede constatar que, dentro de la miscelánea de usos de recursos naturales, la cura para el cuerpo y para el espíritu por medio de uso de plantas se mostró notoria en la comunidad, tornándose necesario el registro y la valorización de esta práctica, esencial para la conservación y el mantenimiento de la diversidad biológica y cultural.

Palabras clave: Comunidad Aroeiras; Conocimientos Tradicionales; Etnobotánica; Plantas Mágicas.

\section{INTRODUÇÃO}

O ser humano sempre foi dependente do uso dos recursos vegetais para a sua sobrevivência e essa utilização vai desde as necessidades mais basais, como alimento e medicina, até finalidades mágicas, ritualísticas e simbólicas. Entretanto, ele não é só dependente, mas também manipulador de paisagens e responsável por uma parte da coevolução com as plantas (Boscolo 2013). O homem primitivo desde cedo procurou na natureza as soluções para os vários males que o afligiam, fossem estes de ordem espiritual ou física. Aos feiticeiros, considerados intermediários entre os deuses e os seres humanos, competia a tarefa de curar os doentes, unindose desta forma magia e religião ao conhecimento empírico das práticas de saúde, como no uso de vegetais medicinais. A era antiga inaugurou outro enfoque, quando os processos de cura deixaram de ser concebidos apenas sob um caráter espiritual e/ou místico (Alvim et al. 2006).

Costa (2008) também ressalta que além de determinante na manutenção da vida como alimento, utensílio e abrigo, a beleza das plantas já causou admiração e espanto aos homens. O aspecto terapêutico das plantas, envolto em mitos, na antiguidade, inspirou os curandeiros e feiticeiros a perseguir o conhecimento relativo ao domínio e aplicação das ervas, pois, essa seria uma forma de conquistar o poder. Meira (2013) pontua que, nos dias de hoje, mesmo tendo acesso a outros meios de conhecimentos, permaneceu aquela ideia de que algumas plantas possuem certos poderes "mágicos", isto é, a capacidade de ajudar a solucionar determinadas angústias da sociedade (acalmar, excitar, curar etc.). Na cosmovisão de Laplantine e Rabeyron (1989), a medicina popular pode estar atrelada às práticas de prevenção e de cura, fundamentadas numa visão do homem e do cosmos que estes qualificam antropologicamente de 'mágica'.

Dentro da pluralidade da utilização de plantas, pode-se destacar a prática de uso de vegetais por rezadores, usualmente católicos, que em cujos rituais de rezas e benzeduras, integram o uso de certo vegetal para finalidades de ações terapêuticas nos processos ritualísticos (Oliveira e Trovão 2009).

Para famílias de localidades rurais, os quintais podem ser considerados como importantes sistemas de produção os quais são complementares às outras maneiras de uso da terra, como a roça e a floresta, compreendendo benefícios tangíveis, como o cultivo de espécies alimentícias e a extração de matérias-primas, e benefícios que 
são difíceis de mensurar, relacionados a aspectos estéticos, de lazer, bem como aos valores emocionais atrelados a sua cultura e tradições (Lok 1998; Garrote 2004).

A transmissão oral de saberes sobre o uso dos vegetais pelas comunidades humanas é praticada a gerações. Contudo, o processo de modernização e a busca de novos meios de comunicação estão levando à perda desta tão valiosa forma de transmissão. Outro fator que se soma a esta perda cultural é a destruição do habitat natural onde estas comunidades estão inseridas (Brito e Brito 1996). Entretanto, falando sobre as implicações culturais dessa dinâmica de transformação e/ou evolução no espaço rural, Kruger e Shannon (2000) argumentam que a identidade cultural dessas comunidades, desenvolvida a partir da conexão cognitiva, emocional e simbólica com os recursos vegetais, não é afetada apenas em sua intensidade, mas em seu processo como um todo.

A investigação etnobotânica desempenha funções de grande relevância como agrupar informações sobre todos os possíveis usos de plantas, como uma contribuição para o desenvolvimento de novas maneiras de exploração dos ecossistemas que se oponham às formas destrutivas vigentes. Os saberes e as tecnologias tradicionais, enriquecidos pelo conhecimento científico ocidental, podem ser desenvolvidos tanto a nível local das comunidades estudadas, como a níveis mais abrangentes, dentro de programas regionais de desenvolvimento, entendendo-se estes não apenas como um novo estilo de desenvolvimento mais racional, porém, como parte de uma estratégia política para o intercâmbio social (Caballero 1983).

Nesse sentido, este trabalho tem por objetivo repertoriar as plantas de uso místico cultivadas nos quintais da comunidade rural Aroeiras, Monsenhor Hipólito-PI, além de suas indicações terapêuticas, para assim obter subsídios para uma melhor compreensão e análise do papel destas plantas no contexto cultural local, resgatando e preservando-se tais conhecimentos, pois, em meio às modificações do campo, uma vez perdidos, estes saberes de usos imateriais se tornam irrecuperáveis.

\section{Materiais e MÉtodos}

\section{Caracterização da área de estudo}

O município de Monsenhor Hipólito está inserido na microrregião de Pio IX no estado do Piauí, no território de Desenvolvimento Vale do Guaribas, ocupando uma área territorial de 401,33 km². Segundo dados censitários do Instituto Brasileiro de Geografia e Estatística, a população do município corresponde a 7.391 habitantes, sendo 52,84\% desta população assentada em áreas rurais (IBGE, 2010).

Localizado nas coordenadas $06^{\circ} 59^{\prime} 47^{\prime}$ 'S e $41^{\circ} 01^{\prime} 47^{\prime \prime} \mathrm{O}$, limita áreas ao norte com o município de Pio IX, ao sul com Campo Grande do Piauí, com Francisco Santos a oeste e ao leste com Alagoinhas do Piauí e Campo Grande do Piauí (Aguiar e Gomes 2004). De clima tropical semiárido e quente, o município hipolitano apresenta um misto no seu extrato vegetal de caatinga e cerrado sub-caducifólio. No contexto geológico, apresenta uma única unidade pertencente às coberturas sedimentares, o Grupo Serra Grande, reunindo solos que são derivados da alteração de arenitos, folhelho, conglomerado e siltito (Jacomine 1986).

Considerando as 17 comunidades rurais da referida cidade (Aguiar e Gomes 2004), Aroeiras foi a comunidade foco deste estudo, a qual dista 13 quilômetros da sede municipal (Figura 1). Aroeiras é uma comunidade ampla e de fácil acesso, recortada pelas rodovias PI-229 e pela BR-020. Possui uma escola pública municipal, a unidade Antônio Hipólito, que oferece o ensino fundamental I e II e um posto de saúde que atende a necessidades 
primárias de saúde. A religiosidade local é registrada principalmente pelo catolicismo, contendo uma igreja que foi construída pelos moradores da região, templo de devoção a Nossa Sra. do Perpétuo Socorro, padroeira local, festejada com novenário, missas e leilão durante o mês de setembro.

Figura 1 - Mapa da localização do município de Monsenhor Hipólito-Piauí e da comunidade rural Aroeiras
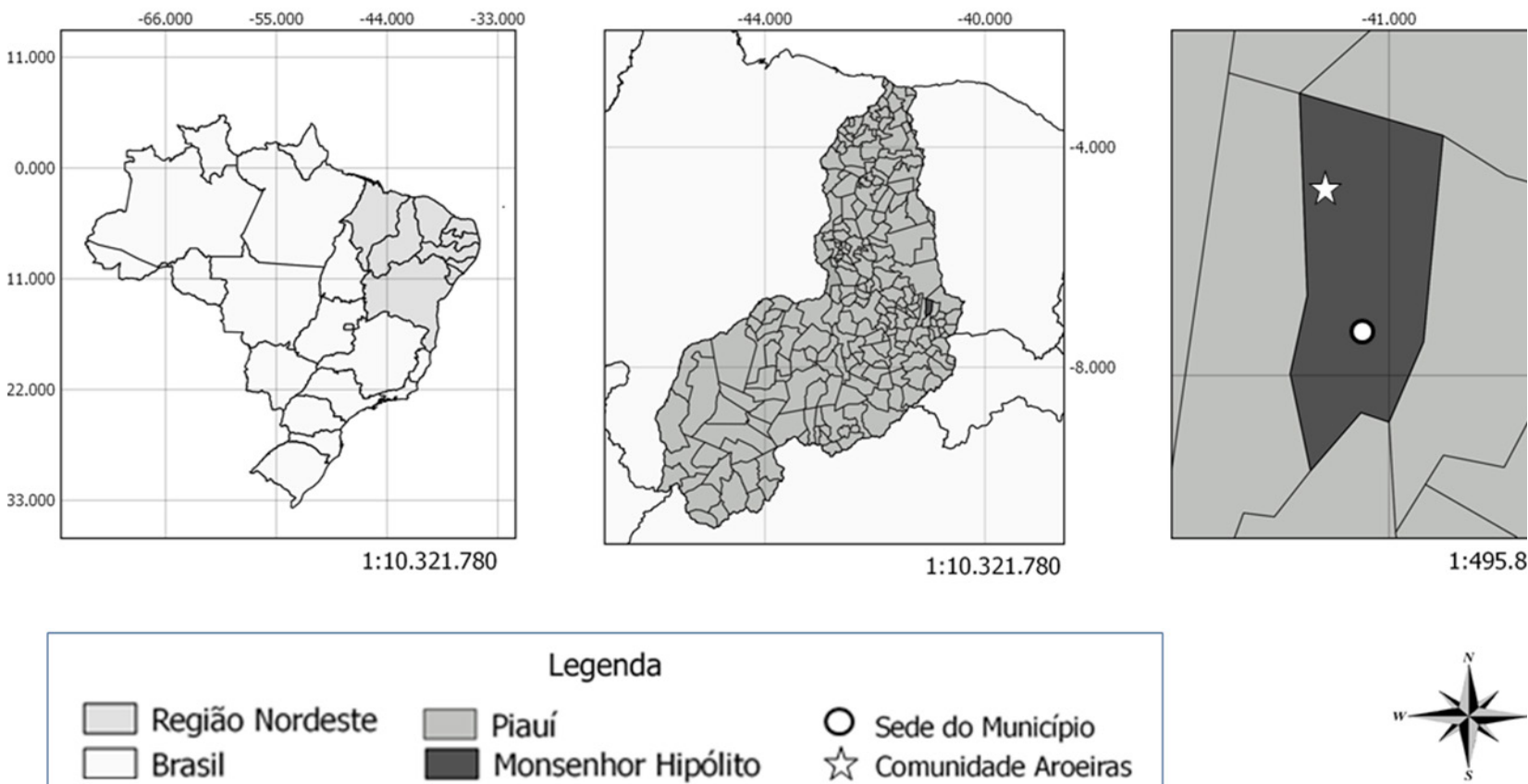

Conforme informações cedidas através do Programa Saúde da Família local, na área ocorrem 127 domić́lios com cerca de 740 moradores (PSF 2014), organizados basicamente no grupo familiar, sobrevivendo, sobretudo, de atividades agrícolas, principalmente da produção de feijão, milho e mandioca, bem como da colheita e produção do caju, combinado com o criatório de animais de pequeno porte, como porcos e galinhas, além do gado (Abreu et al. 2017).

\section{Coleta e análise de dados}

A coleta de dados foi feita através de excursões em dias irregulares entre fevereiro e maio de 2014 à comunidade estudada, cujas ferramentas metodológicas incluíram entrevistas semiestruturadas e turnês-guiadas (Bernard 1988). As entrevistas semi-estruturadas por meio formulários continham questões abertas (open-ended) e fechadas (closed-ended) (Albuquerque et al. 2010) e os formulários além de questões etnobotânicas sobre as plantas místicas cultivadas nos quintais, também abordava aspectos socioeconômicos dos entrevistados.

Para a coleta de dados foi levado em consideração as exigências contidas na Resolução 466/12 do Conselho Nacional de Saúde, que regulamenta a pesquisa com seres humanos (Brasil, 2012). Para tanto, após a explicação do objetivo da pesquisa, foi solicitada a permissão da mesma, por meio da assinatura Termo de Consentimento Livre e Esclarecido (TCLE), pesquisa esta de natureza descritiva e de abordagem quali-quantitativa que faz parte do projeto de pesquisa aprovado pelo Comitê de Ética em Pesquisa da Universidade Federal do Piauí (UFPI), sob parecer de apreciação de número CAAE 27210114.5.0000.5214.

A seleção dos quintais estudados foi feita pela amostragem "bola de neve" (snowball) (Bailey 1994), e para finalidades deste estudo, o jardim também foi considerado parte integrante do quintal (Van Holthe 2003), onde 
é composto principalmente por plantas ornamentais, além de toda a área externa à casa com plantas cultivadas em vasos ou diretamente na terra (Trotta et al. 2012).

Sempre que possível, coletou-se amostras férteis dos vegetais, realizando-se registro fotográfico das mesmas, bem como das informações pertinentes em diário de campo (hábito, altura da planta, coloração de flores e frutos). Ressalte-se que foi considerado apenas um único registro da espécie por quintal, sendo que as etnoespécies coletadas foram herborizadas de acordo com procedimentos usuais de campo propostos por Mori et al. (1989). O material botânico processado e identificado, consoante literatura especializada, foi incorporado ao acervo do futuro Herbário de Picos. A nomenclatura dos táxons, correções e abreviações dos nomes dos autores foi feita através da base de dados do sítio do Missouri Botanical Garden (http:/ wwww.tropicos.org). O sistema taxonômico de listagem dos taxa foi com base em APG IV (2016). Os dados referentes ao status das espécies de nativa ou exótica seguiu Font-Quer (1982), e para a origem delas Lozano et al. (2014), assim como consultas às obras de Lorenzi e Matos (2008) e Sousa e Lorenzi (2012).

Os dados obtidos foram organizados em planilhas do Microsoft Excel 2010, para proceder-se à análise quantitativa das informações. Uma lista foi organizada contendo nomes científicos, vulgares, indicações, hábitos e origem. Famílias, gêneros e espécies encontram-se dispostas ordem alfabética.

Além disto, calculou-se o Valor de Uso $(\mathrm{VU}=\Sigma \mathrm{U} / \mathrm{n}$, onde, $\mathrm{VU}=$ Valor de $\mathrm{Uso}, \mathrm{U}=$ número de citações da etnoespécie por informante, $\mathrm{n}=$ número de informantes que citaram a etnoespécie) das espécies, empregando a técnica sugerida por Phillips e Gentry (1993 a,b) e Phillips et al. (1994), modificada por Rossato (1996), onde a importância de uma espécie vegetal é dada pelo número de usos representado por ela.

\section{Resultados e Discussão}

Compreendendo inicialmente os aspectos dinâmicos da comunidade estudada, 71 quintais foram pesquisados, contabilizando 71 entrevistados, dos quais $87,32 \%$ são do sexo feminino. Em estudos realizados por outros autores, as mulheres também corresponderam a maior parte dos entrevistados (Cunha e Bortolotto 2011; Carvalho et al. 2013; Gonçalves e Pasa 2015; Silva et al. 2015).

Para a faixa etária, 73,24\% do universo de entrevistados apresentam idade igual ou superior a 41 anos de idade, sendo mais expressiva a faixa compreendida entre 61 e 70 anos com 23,94\% dos participantes. Apenas uma minoria (5,63\%) apresentou idade igual ou menor a 30 anos. Vendruscolo e Mentz (2006) indicaram a maior parte dos entrevistados no intervalo etário de 40 a 70 anos de idade.

Acerca do estado civil, 77,46\% apresentam estabilidade na relação conjugal, onde 71,83\% são casados mesmos, seja religiosa ou legalmente; 9,86\% são solteiros e 12,68\% viúvos. Segundo Freitas et al. (2012) a classe casada poderá estar relacionada com maior conhecimento sobre as plantas, uma vez que, comumente, a existência dos filhos implica na procura de soluções práticas e imediatas para a terapêutica de doenças. No tocante à escolaridade, a pesquisa indica o índice de 45,07\% para ensino fundamental incompleto, compondo o percentual mais expressivo, seguido por 32,39\% de não escolarizados. Situação semelhante também é observada por Batista et al. (2016) na comunidade rural Novo Nilo, União-PI, onde 47,5\% dos participantes apresentaram ensino fundamental incompleto e 31,7\% sem escolaridade. Oliveira e Menini Neto (2012) também apontam a maioria dos entrevistados com baixo nível de escolaridade, atrelando o trabalho pesado ligado à agricultura à inviabilização dos estudos. 
Profissionalmente, quase a totalidade se declarou agricultores (95,77\%) vivendo principalmente das atividades agrícolas de subsistência. Destes, 33,80\% afirmaram ser aposentados ou pensionistas do Instituto Nacional do Seguro Social (INSS), mas que mesmo assim ainda desempenham "atividades da roça". Quanto à renda familiar, 67,61\% compreendem até um salário-mínimo de renda e quase a totalidade residia em casa própria, só um participante morava em casa cedida por terceiros.

Referindo-se ao tempo de vivência dos entrevistados na comunidade, a maior parte vivia a um período superior a 10 anos $(60,56 \%)$ e, apenas, 18,31\% vivia no local desde que nasceu. Sobre a religiosidade, todos os participantes afirmaram ser católicos.

No levantamento florístico, dentro do conjunto vegetal de uso místico, considerou-se aí pertencentes as plantas que eram utilizadas no tratamento de problemas espirituais, como amuletos de sorte, capacidade de afastar mau-olhado, para ocasionar bons presságios e proteção, dentre outros significados (Silva e Andrade 2005). Dos 71 moradores pesquisados, a maior parte afirmou cultivar algum tipo de vegetal místico em seus quintais $(85,91 \%)$. Apenas em 10 quintais não se registrou plantas de tais usos.

Dos quintais com algum vegetal místico cultivado, em 17 registrou-se apenas uma planta; em 20 quintais, duas plantas; em 11, três plantas; quatro plantas de uso místico em 4 quintais; cinco plantas em 2 quintais e seis plantas em apenas 1 quintal (figura 2).

Figura 2 - Porcentagem dos moradores entrevistados que afirmaram cultivar ou não alguma planta de uso místico em seus quintais na comunidade rural Aroeiras, Monsenhor Hipólito-PI.

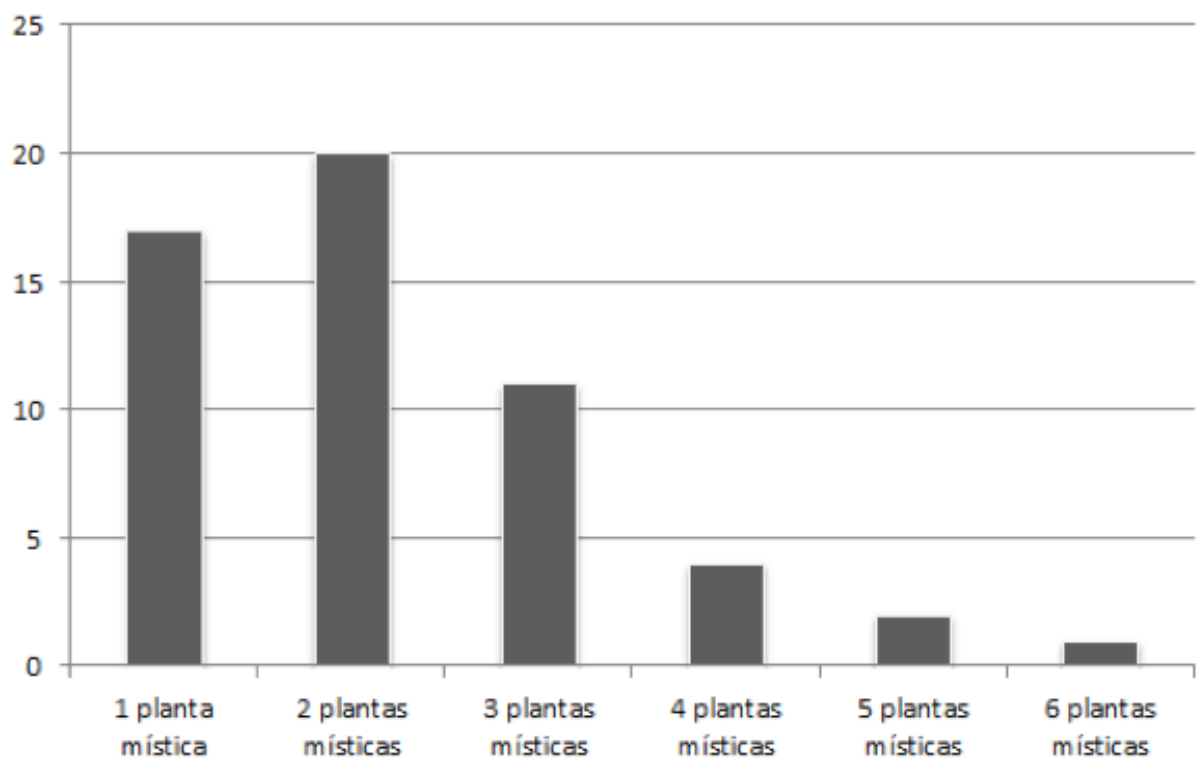

Assim, a pesquisa possibilitou registrar 12 espécies místicas, pertencentes a 8 famílias botânicas, sendo a família Cactaceae a mais expressiva, incluindo 5 diferentes espécies; todas as demais famílias compreenderam uma única espécie. Dentre estas espécies, a maioria possui hábito herbáceo, metade delas é de origem exótica e metade nativa (Tabela 1$)$.

Vários trabalhos etnobotânicos sobre o uso de plantas indicam a utilização de vegetais para finalidades místicas, ritualísticas, simbólico-afetiva e/ou mágico-religioso, contribuindo para a expansão do etnoconhecimento dentro da pluralidade de usos dos vegetais. Dentre estes trabalhos, pode-se citar: Shardong e Cervi (2000) na comunidade de São Benedito, Campo Grande-MS; Amorozo (2002) em Santo Antônio do Leverger-MT; 
Fonseca-Kruel e Peixoto (2004) na Reserva Extrativista do Arraial do Cabo no Rio de Janeiro; Oliveira e Trovão (2009) no estado da Paraíba; Souza e Guarim Neto (2010) em comunidades ribeirinhas em Cuiabá; Trotta el al. (2012) em quintais urbanos de São Paulo e Miranda et al. (2016) em quintais urbanos de Abaetetuba-PA.

Tabela 1 - Espécies místicas cultivadas em quintais pelos moradores da comunidade rural Aroeiras, município de Monsenhor Hipólito-PI. O: origem: e=exótica, $\mathrm{n}=$ nativa. $\mathrm{H}=$ Hábito: arb=arbusto, erv=erva, sub=subarbusto; Fr: frequência relativa e VU=Valor de Uso.

\begin{tabular}{|c|c|c|c|c|c|}
\hline $\begin{array}{c}\text { FAMÍLIA/ESPÉCIE (NOME } \\
\text { VULGAR) }\end{array}$ & $\mathbf{O}$ & $\mathbf{H}$ & INDICAÇÕES & Fr & VU \\
\hline $\begin{array}{c}\text { ACANTHACEAE } \\
\text { Justicia gendarussa Burm. f. } \\
\text { (abre-caminho) }\end{array}$ & $\mathrm{e}$ & arb & inveja, uso ornamental & 6 & 1,83 \\
\hline $\begin{array}{c}\text { ASPARAGACEAE } \\
\text { Sansevieria trifasciata var. laurentii (De } \\
\text { Wild.) N. E. Br. } \\
\text { (espada-de-são-jorge) } \\
\text { CACTACEAE }\end{array}$ & $\mathrm{e}$ & erv & $\begin{array}{l}\text { mau-olhado, proteger } \\
\text { residências, uso ornamental }\end{array}$ & 14 & 1,93 \\
\hline $\begin{array}{l}\text { Cereus jamacaru DC. } \\
\qquad(\text { mandacaru })\end{array}$ & $\mathrm{n}$ & arb & $\begin{array}{l}\text { mau-olhado, olho gordo, espantar coisas } \\
\text { negativas, pedra nos rins, inflamações em } \\
\text { geral, uso ornamental }\end{array}$ & 12 & 1,42 \\
\hline $\begin{array}{c}\text { Echinopsis arachnacantha (Buining \& F. } \\
\text { Ritter) Friedrich } \\
\text { (panta) }\end{array}$ & $\mathrm{n}$ & erv & mau-olhado, olho gordo, uso ornamental & 7 & 1,57 \\
\hline $\begin{array}{c}\text { Melocactus zehntneri (Britton \& Rose) } \\
\text { Luetzelb } \\
\text { (coroa-de-frade) }\end{array}$ & $\mathrm{n}$ & erv & $\begin{array}{c}\text { mau-olhado, espantar coisas negativas, } \\
\text { uso ornamental }\end{array}$ & 28 & 1,61 \\
\hline $\begin{array}{l}\text { Opuntia ser. Brasilienses } \\
\text { (quipazinho) }\end{array}$ & $\mathrm{n}$ & erv & mau-olhado, uso ornamental & 3 & 1,00 \\
\hline $\begin{array}{c}\text { Pilosocereus gounellei (F. A. C. Weber) } \\
\text { Byles \& G. D. Rowley } \\
\text { (xique-xique) }\end{array}$ & $\mathrm{n}$ & arb & $\begin{array}{l}\text { mau-olhado, coisas 'ruins', } \\
\text { uso ornamental }\end{array}$ & 2 & 1,50 \\
\hline $\begin{array}{l}\text { EUPHORBIACEAE } \\
\text { Jatropha gossypiifolia } \mathrm{L} \text {. } \\
\text { (pinhão-roxo) } \\
\text { LAMIACEAE }\end{array}$ & $\mathrm{e}$ & arb & $\begin{array}{l}\text { mau-olhado, quebranto, espantar coisas } \\
\text { ruins, benzer crianças }\end{array}$ & 30 & 1,53 \\
\hline $\begin{array}{l}\text { Rosmarinus officinalis } \mathrm{L} \text {. } \\
\text { (alecrim) }\end{array}$ & $\mathrm{e}$ & sub & $\begin{array}{l}\text { mau-olhado, inveja, gripe, resfriado, } \\
\text { dor de cabeça }\end{array}$ & 4 & 2,75 \\
\hline $\begin{array}{c}\text { PHYTOLACCACEAE } \\
\text { Petiveria alliaceae } \mathrm{L} \text {. } \\
\text { (tipi) } \\
\text { RUTACEAE }\end{array}$ & $\mathrm{e}$ & erv & $\begin{array}{l}\text { mau-olhado, ressecamento, } \\
\text { reumatismo, gripe }\end{array}$ & 2 & 2,50 \\
\hline
\end{tabular}


mau-olhado, olho gordo, espantar

Ruta graveolens L.

(arruda)

e sub

coisas 'ruins', dor de ouvido, problemas

nos olhos, analgésico, problemas femininos, dor de barriga

\section{SOLANACEAE}

Capsicum annuum var. glabriusculum

(Dunal) Heiser \& Pickersgill

(pimenta-de-mesa) n sub

mau-olhado, inveja, uso ornamental
10 
a panema' (azar) e 'abrir os caminhos', ou usadas em 'banhos de descarrego'. As principais espécies com essas utilidades citadas foram: comigo-ninguém-pode (Dieffenbachia sp.), arruda (R. graveolens L.), tipi (P. aliacea L.), pinhão-roxo (J. gossypiïfolia L.) e espada-de-são-jorge (Sansevieria sp.).

As plantas místicas mais citadas foram a J. gossypiifolia (pião-roxo), M. ̨ehntneri (coroa-de-frade), S. trifasciata var. laurentii (espada-de-são-jorge), C. jamacaru (mandacaru) e R. graveolens (arruda), encontradas em, respectivamente, 30, 28, 14, 12 e 10 quintais, indicadas principalmente para cura de doenças culturais, como quebrate, mauolhado, olho-gordo, e espantar coisas negativas como um todo. As demais plantas foram encontradas em um número menor de domićlios.

Para o valor de uso, $R$ graveolens $(3,10)$ e $R$. officinalis $(2,75)$ foram as espécies que se encontrou os maiores valores, as quais além do uso para causas imateriais, também tiveram indicações tangíveis, na esfera medicinal para debelar enfermidade, podendo-se constatar que estas são aquelas cujo conhecimento ao seu respeito é mais equitativamente distribuído dentro do grupo estudado, mesmo não sendo as de maior número de cultivo nos quintais.

Pereira et al. (2016) em quintais de comunidades rurais de Monsenhor Gil-PI mencionaram apenas quatro espécies místicas, das quais três foram citadas nesta pesquisa: S. trifasciata var. Laurentii (De Wild.) N. E. Br. (espada-de-são-jorge), J. gossypiifolia L. (pinhão-roxo) e P. alliacea L. (tipi), cujas são colocadas na frente das residências para espantar o "mau-olhado".

As doenças culturais são muito populares em comunidades rurais e servem para explicar sintomas de outras doenças que não foram identificadas pela população naquele momento específico (Roque 2010). Cascudo (2001) em seu livro sobre supertições no Brasil discorre acerca do mau-olhado ou olhos maus como sendo uma alteração de saúde, causada por influência de olhos maus, afirmando que certas pessoas têm, nos olhos, o poder de fazer murchar as plantas, adoecer as pessoas, fazer com que os negócios dos outros não deem certo, além de que, segundo a crença, essa "doença” pode levar a óbito.

Lorenzi e Matos (2008) realçam o uso do J. gossypiifolia no Nordeste do Brasil como planta mágica, que é plantada em frente da casa de moradias, evitando a entrada de todos os males. Oliveira (2008) estudando comunidades rurais da cidade de Oeiras-PI também enfatiza que na frente das residências pesquisadas é encontrada tal espécie plantada para espantar mau-olhado e trazer bons presságios, fato este também observado nos domicílios pesquisados, uma vez que as plantas de uso místico e/ou simbólico predominavam principalmnete na frente das casas, funcionando assim como amuletos para aquebrantar e impedir a entrada de possíveis males e vibrações negativas nas casas.

O pião-roxo também foi citado no uso de práticas ritualísticas, envolvendo o benzimento de crianças com folhas da referida planta. Pereira et al. (2016), em cenário semelhante no Piauí, também mencionam o uso do pião-roxo em rituais, onde rezadores utilizam um pequeno galho da planta que é passado sobre o corpo da pessoa acompanhado de uma reza, sendo utilizadas principalmente para tirar quebranto e mau-olhado.

A prática da benzeção é uma expressão da cultura popular que envolve o desdobramento tanto de aspectos do catolicismo quanto da medicina popular para a resolução de questões relacionadas à saúde. Os símbolos são percebidos nos rituais de cura que existem em diversas culturas e são marcados por experiências religiosas singulares, possuindo diferenciações de acordo com as atribuições de sentidos dados pelas comunidades que os criam e recriam, cotidianamente (Geertz 2008), fazendo assim parte da tradição do povo brasileiro, seja no meio urbano ou rural (Maciel e Neto 2006). 
Percebeu-se, na comunidade Aroeiras, a crença de que as plantas contendo espinhos são úteis para proteção dos indivíduos e dos lares contra todo tipo de energia negativa que possa pairar sobre estes, servindo como escudos e/ou amuletos protetivos aos que cultivam em suas dependências, explicando desta maneira a expressividade das cactáceas. Acerca deste grupo, Lucena et al. (2012a) e Lucena et al. (2012b) ilustram sobre a extrema importância destas para a vida das pessoas que residem na zona rural do semiárido brasileiro, indicando sua multiplicidade de usos, que vai desde o uso alimentício, passando pela utilidade para debelar patologias de atenção primária, até usos abstratos, envolto em mitos e crendices populares. C. jamacaru, Melocactus sp. e $P$. gounellei são citados nestes trabalhos em categorias mágicas.

A arruda (R. graveolens) dentro do simbolismo local, foi referida como planta de grande sensibilidade, onde nem todos podem colhê-la (pois pode levá-la ao murchamento e a morte), bem como por exalar um forte cheiro típico quando a residência é visitada por pessoas tidas como "ruins" (entenda-se como aquelas que são carregadas negativamente). Analogamente, Patzlaff (2007), em uma comunidade do Rio de Janeiro também aponta que a arruda, assim como outras plantas mágicas, só pode ser colhida pelo dono, pois outros indivíduos podem ter a "mão ruim", e ao tocarem a planta podem causar a sua morte. O mesmo autor acredita que, possivelmente, tais essas crenças populares originam-se de religiões de matriz africana assim como também da tradição de rezadeiras.

A C. annum var. glabriusculum também foi registrada no trabalho de Nascimento Filho et al. (2007) como mágica, e informam ser a mesma comercializada em pequenos vasos, nas feiras de Roraima, para fins ornamentais e como talismã contra o "mau-olhado". Historicamente, as pimentas Capsicum sp. têm exercido importante papel como plantas dotadas de poderes mágicos e utilizadas em cerimoniais religiosos e de cura entre povos americanos (Grenand et al. 2004). Do mesmo modo, em investigações botânicas efetivadas em outros continentes, registrou-se o emprego destas no tratamento de doenças de "ordem espiritual".

O tipi (P. alliacea) é referido por Camargo (1988) como amuleto protetor contra espíritos obsessores e limpeza espiritual de pessoas e lugares. Braga (1992) recorrendo ao passado, menciona o uso deste em cerimônias religiosas pelos escravos que a chamavam de "remédio amansa senhor", aludindo a suas propriedades mágicas, tóxicas e sedativas. A espécie Justicia gendarussa, conhecida popularmente como abre-caminho, também é indicada como mística em trabalhos desenvolvidos por Ferreira (2014) no Espírito Santos e em Albuquerque et al. (2007) no nordeste brasileiro, de natureza igual ao alecrim (R. officinalis) em quintais urbanos de São Paulo em Trotta et al. (2012).

Com enfoque ao valor simbólico-cultural dos vegetais citados, importa salientar que, através de estudos que relacionem as potencialidades das plantas disponíveis em uma determinada comunidade, pode-se traçar planos de recuperação e de conservação para a área estudada, onde a otimização dos usos originais atribuídos podem ampliar as perspectivas das gerações futuras ao usufruírem destes recursos, já que quando se une o natural e o cultural, obtêm-se espécies de maior valor simbólico, facilitando a luta pela sua conservação e manutenção biológica e cultural (Roque et al. 2010).

\section{Conclusão}

Deste modo, imersos em crendices, sensações, mistérios, rituais, conotações esotéricas e demais manifestações culturais, o conhecimento popular das plantas de uso místico em menor ou maior grau faz 
referência a um conteúdo cultural que perpassou o tempo e muitas gerações. E, dentro da miscelânea de usos dos recursos naturais, a cura para o corpo e para o espírito permeia o universo vegetal local, dado este corroborado pelas 12 espécies de uso místico cultivadas nos quintais da comunidade Aroeiras, as quais são utilizadas para satisfazer necessidades imateriais.

$\mathrm{O}$ aspecto místico dos vegetais presentes na comunidade revela o caráter tradicional que ainda figura entre os moradores locais, bem como a notória presença de concepções empíricas, mesmo em meio à forte pressão da modernização que recai sobre as comunidades face à novos padrões culturais.

Assim, pesquisar, registrar e valorizar os significados incorporados por meio de símbolos, rituais e crenças das comunidades rurais, resultados da interação homem/planta se faz necessário, uma vez que tais práticas envolvendo os vegetais podem funcionar como importantes ferramentas à conservação e manutenção da diversidade biológica e cultural, muitas vezes específica de uma determinada região, já que cada povo adota critérios únicos para o aproveitamento dos recursos que estão ao seu alcance, impedindo desta forma a perda de tais conhecimentos.

\section{REFERÊNCIAS}

Abreu MC, Silva PH, Oliveira YR. 2017. Vegetais cultivados em quintais rurais piauienses com indicação anticâncer: uma busca pelo conhecimento tradicional. Ciência e Natura, 39(1):22 -32.

Aguiar RB e Gomes JRC. 2004. Projeto cadastro de fontes de abastecimento por água subterrânea, estado do Piauí: diagnóstico do município de Monsenhor Hipólito. Fortaleza: CPRM - Serviço Geológico do Brasil, 2004.

Albuquerque UP, Monteiro JM, Ramos MA, Amorim EL. 2007. Medicinal and magic plants from a public market in northeastern Brazil. Journal of Ethnopharmacology, 110:76-91.

Albuquerque UP, Lucena RFP e Alencar NL. 2010. Métodos e técnicas para coleta de dados etnobiológicos. In: Métodos e técnicas na pesquisa etnobiológica e etnoecológica. Recife: NUPPEA, p.39-64.

Alvim NAT, Ferreira MA, Cabral IE e Almeida Filho AJ. 2006. O uso de plantas medicinais como recurso terapêutico: das influências da formação profissional às implicações éticas e legais de sua aplicabilidade como extensão da prática de cuidar realizada pela enfermeira. Revista Latino-Americana de Enfermagem, 14(3):316-323.

Amorozo MCM. 2002. Uso e Diversidade de Plantas Medicinais em Santo Antônio do Leverger, MT, Brasil. Acta Botanica Brasilica, 16(2):189-203.

Andrade CTS, Marques JGW , Zappi DCC. 2006. Utilização medicinal de cactáceas por sertanejos baianos. Revista Brasileira de Plantas Medicinais, 8(3):36-42.

APG IV (Angiosperm Phylogeny Group). 2016. An update of the Angiosperm Phylogeny Group classification for the orders and families of flowering plants: APG IV. Botanical Journal of the Linnean Society, 181(1):120. 
Bailey K. 1994. Methods of social research. $4^{\text {a }}$ ed. New York: The Free Press, 588 p.

Batista WFM, Santos KPP, Figueiredo LS, Barros RFM. 2016. Sociedade e Cultura: O caso da Comunidade Rural Novo Nilo. Espacios, 37(3):20.

Bernard HR. 1988. Research methods in cultural anthropology. Newbury Park, CA: Sage Publ., 520 p.

Bastide R. 1971. As religiões africanas no Brasil. São Paulo: Pioneira, 567 p.

Braga RA. 1992. Plantas do Nordeste, especialmente do Ceará. Coleção Mossoroense. $3^{a}$ ed. Mossoró: ESAM, 540 p.

Brasil. 2012. Ministério da Saúde, Conselho Nacional de Saúde. Comissão Nacional de Ética em Pesquisa: normas para pesquisa envolvendo seres humanos (Res. CNS 466/12 e outros) Brasília, DF. Disponível em: <http://conselho.sa ude.gov.br/resolucoes/2012/ Reso466.pdf> Acesso em: 19 Dez. 2016.

Brito ARM e Brito AAS. 1996. Medicinal plant research in Brazil: data from regional and national meetings. In: Medicinal Resources of the tropical forest - biodiversity and its importance to human health. New York : Columbia University Press, p. 386-401.

Boscolo OH. 2013. Para comer, para beber ou para remédio? Categorias de Uso múltiplo em Etnobotânica. Cadernos UniFOA, 1:61-67.

Caballero NJ. 1983. Perspectivas para el que hacer etnobotánico en México. In: La etnobotánica: três puntos de vista y una perspectiva. Xapala: Instituto Nacional de Investigaciones sobre Recursos Bióticos, p. 25-28.

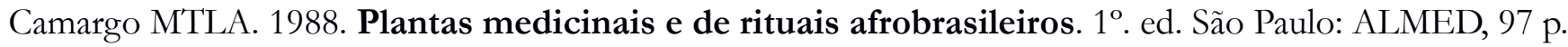

Camargo MTLA. 2007. Contribuição etnofarmacobotânica ao estudo de Petiveria alliacea L. -Phytolacaceae(“amansa-senhor") e a atividade hipoglicemiante relacionada a transtornos mentais. Dominguezia, 23(1):21-27.

Camargo MTLA. 2000. Breve estudo da influência portuguesa na medicina popular do Brasil desde seu descobrimento. Jornada de Estudos Medievais Aracaju. Disponível em: < $\underline{\text { http://www.aguaforte.com/ }}$ herbarium/influenciaportuguesa.html>. Acesso em 05 jan. 2017

Carvalho JSB, Martins JDL, Mendonça MCS, Lima LD. 2013. Uso popular das plantas medicinais na comunidade da Várzea, Garanhuns-PE. Revista de Biologia e Ciências da Terra, 13(2):58-65.

Cascudo LC. 2001. Superstição no Brasil. 4.ed. São Paulo: Global, 496 p.

Costa VF. 2008. A origem da fitoterapia na humanidade e a recente aplicação em animais selvagens, Universidade Castelo Branco, Brasília, 82p.

Cunha AS, Bortolotto IM. 2011. Etnobotânica de Plantas Medicinais no Assentamento Monjolinho, município de Anastácio, Mato Grosso do Sul, Brasil. Acta Botanica Brasilica, 25(3):685-698.

Geertz C. 2008. A interpretação das culturas. $1^{\text {a }}$ ed. Rio de Janeiro: LTC. 323 p. 
Farelli MH. 1994. Plantas que curam e cortam feitiços. 4. ed. Rio de Janeiro: PALLAS.

Ferreira JM. 2014. Plantas de uso medicinal e ritualístico comercializadas em mercados e feiras no Norte do Espírito Santo, Brasil, Universidade Federal do Espírito Santo, São Mateus. 99 p.

Fonseca-Kruel VS, Peixoto AL. 2004. Etnobotânica na Reserva Extrativista Marinha de Arraial do Cabo, RJ, Brasil. Acta Botanica Brasilica, 18(2):177-190.

Font-Quer MP. 1982. Diccionario de botanica. Barcelona: Labor, 1244p.

Freitas AVL, Coelho MFB, Maia SSS, Azevedo RAB. 2012. Plantas medicinais: um estudo etnobotânico nos quintais do Sítio Cruz, São Miguel, Rio Grande do Norte, Brasil. Revista Brasileira de Biociências, 10(1):4859.

Garrote V. Os quintais caiçaras, suas características sócio-ambientais e perspectivas para a comunidade do saco do mamaguá, Paraty-RJ. Universidade de São Paulo, São Paulo, 157 p.

Giraldi M, Hanazaki N. 2010. Uso e conhecimento tradicional de plantas medicinais no Sertão do Ribeirão, Florianópolis, SC, Brasil. Acta Botanica Brasilica, 24(2):395-406.

Gonçalves KG, Pasa MC. 2015. A etnobotânica e as plantas medicinais na Comunidade Sucuri, Cuiabá, MT, Brasil. Interações, 16(2):245-256.

Grenand P, Moretti C, Jacquemin H. 2004. Pharmacopées traditionnelles en Guyanne: Créoles, Wayãpi, Palikur. Paris : IRD, 816 p.

IBGE. 2010. Instituto Brasileiro de Geografia e Estatística. Perfil das cidades piauienses. Disponível em:<http://www.ibge.gov.br/cidadesat/xtras/perfil.php?codmun=220650\&search=piaui $\mid$ monsenhorhipolito >. Acesso em 10 jan. 2017

Jacomine PKT. 1986. Levantamento exploratório - reconhecimento de solos do Estado do Piauí. Rio de Janeiro, EMBRAPA-SNLCS/SUDENE-DRN, 782 p.

Kruger LE, Shannon MA. 2000. Getting to know ourselves and our places through participation in civic social assessment. Society and Natural Resources, 13(5):461-478.

Liporacci HSN, Simão DG. 2013. Levantamento etnobotânico de plantas medicinais nos quintais do Bairro Novo Horizonte, Ituiutaba, MG. Revista Brasileira de Plantas Medicinais, 15(4):529-540.

Lorenzi H e Matos FJA. 2008. Plantas medicinais no Brasil: nativas e exóticas. $2^{\mathrm{a}}$ ed. Nova Odessa: Instituto Plantarum, 544 p.

Lozano A, Araújo EL, Medeiros MF, Albuquerque UP. 2014. The apparency hypothesis applied to a local pharmacopoeia in the Brazilian northeast. Journal of Ethnobiology and Ethnomedicine, 10(2):1-17.

Laplantine F e Rabeyron PL.1989. Medicinas paralelas. São Paulo: Ed. Brasiliense, 120 p. 
Lok R. 1998. Huertos tradicionales de America Central: caracteristicas, beneficios e importancia, desde un enfoque multidisciplinario. Turrialba, Costa Rica: CATIE/AGUILA/ IDR/ETC, 232 p.

Lucena CM, Costa GM, Sousa RF, Carvalho TKN, Marreiros NA, Alves, CAB, Pereira DD, Paiva de Lucena RF. 2012a. Conhecimento local sobre cactáceas em comunidades rurais na mesorregião do sertão da Paraíba (Nordeste, Brasil). Biotemas, 25(3)281-291.

Lucena CM, Costa GM, Carvalho TKN, Guerra NM, Quirino ZGM, Paiva de Lucena RF. 2012b. Uso e conhecimento de cactáceas no município de São Mamede (Paraíba, nordeste do Brasil). Revista de Biologia e Farmácia, 7(2)92-101.

Maciel M, Neto GG. 2006. Um olhar sobre as benzedeiras de Juruena (Mato Grosso, Brasil) e as plantas usadas para benzer e curar. Boletim do Museu Paraense Emílio Goeldi, Ciências Humanas, 2(3): 61-77.

Meira CS. 2013. Plantas do axé e sua fundamentação religiosa: um estudo de caso no terreiro de Umbanda "Caboclo Boiadeiro" (fazenda Buraco do Boi - Poções/ Bahia). Universidade Estadual do Sudoeste da Bahia, Itapetinga, 129 p.

Messias MCTB, Menegatto MF, Prado ACC, Santos BR, Guimarães MFM. 2015. Uso popular de plantas medicinais e perfil socioeconômico dos usuários: um estudo em área urbana em Ouro Preto, MG, Brasil. Revista Brasileira de Plantas Medicinais, 17(1):76-104.

Miranda TG, Oliveira Júnior JF, Martins Júnior AS, Martins ACCT. 2016. O uso de plantas em quintais urbanos no bairro da Francilândia no município de Abaetetuba, Pará, Brasil. Scientia Plena, 12(6):2-18.

Mori AS, Silva LAM, Lisboa G, Coradin L. 1989. Manual de manejo do herbário fanerogâmico. Ilhéus, Porto Alegre, Centro de Pesquisas do Cacau - CEPLAC, 104 p.

Nascimento Filho HR, Barbosa RI, Luz FJF. 2007. Pimentas do gênero Capsicum cultivadas em Roraima, Amazônia brasileira. II. Hábitos e formas de uso. Acta Amazonica, 37(4):561-568.

Roque AA, Rocha RM, Loiola MIB. 2010. Uso e diversidade de plantas medicinais da Caatinga na comunidade rural de Laginhas, município de Caicó, Rio Grande do Norte (nordeste do Brasil). Revista Brasileira de Plantas Medicinais, 12(1):31-42.

Oliveira ER, Menini Neto L. 2012. Levantamento etnobotânico de plantas medicinais utilizadas pelos moradores do povoado de Manejo, Lima Duarte - MG. Revista Brasileira de Plantas Medicinais, 14(2):311-320.

Oliveira ECS, Trovão DMBM. 2009. O uso de plantas em rituais de rezas e benzeduras: um olhar sobre esta prática no estado da Paraíba. Revista Brasileira de Biociências, 7(3):245-251.

Oliveira FCS. 2008. Conhecimento botânico tradicional em comunidades rurais do semiárido piauiense. Universidade Federal do Piauí, Teresina, 134 p.

Patzlaff RG. 2007. Estudo etnobotânico de plantas de uso medicinal e místico na comunidade da Capoeira Grande, Pedra de Guaratiba (RJ) Brasil. Instituto de Pesquisas Jardim Botânico do Rio de Janeiro, 
Escola Nacional de Botânica Tropical, Rio de Janeiro. 160 p..

Pereira LG, Vieira FJ, Alencar NL, Carvalho FPA, Barros RFM. 2016. Diversidade florística em quintais do Nordeste brasileiro: um estudo etnobotânico em comunidades rurais em Monsenhor Gil/PI. Espacios, 37(20):11.

Phillips O, Gentry AH. 1993a. The useful Plants of Tamboapata, Peru: I Statistical hypothesis testing with a new quantitative technique. Economic Botany, 47:15-32.

Phillips O, Gentry AH. 1993b. The useful Plants of Tamboapata, Peru: II Additional hypothesis testing in quantitative ethnobotany. Economic Botany, 47:33-43.

Phillips O, Gentry AH, Reynel C, Wilkin P, Galvez-Durand C. 1994. Quantitative ethnobotany and amazonian conservation. Conservation Biology, 8(1):15-32.

Programa de Saúde da Família - PSF. 2014. Comunidade Aroeiras, Monsenhor Hipólito - PI.

Roque AA, Rocha RM, Loiola MIB. 2010. Uso e diversidade de plantas medicinais da Caatinga na comunidade rural de Laginhas, município de Caicó, Rio Grande do Norte (nordeste do Brasil). Revista Brasileira de Plantas Medicinais, 12(1):31-42.

Rossato SC. 1996. Uso de plantas por comunidades caiçaras do litoral norte do estado de São Paulo. Universidade de São Paulo, São Paulo, 119 p.

Schardong RMF, Cervi AC. 2000. Estudos etnobotânicos das plantas de uso medicinal e místico na comunidade de São Benedito, bairro São Francisco, Campo Grande, MS, Brasil. Acta Biológica Paranaense, 9(1/4):187-217.

Silva MDP, Marini FS, Melo RS. 2015. Levantamento de plantas medicinais cultivadas no município de Solânea, agreste paraibano: reconhecimento e valorização do saber tradicional. Revista Brasileira de Plantas Medicinais, 17(4):881-890.

Silva AJR, Andrade LHC. 2005. Etnobotânica nordestina: estudo comparativo da relação entre comunidades e vegetação na Zona do Litoral - Mata do Estado de Pernambuco, Brasil. Acta Botanica Brasilica, 19(1):45-60.

Siviero A, Delunardo TA, Haverroth M, Oliveira LC, Ronan ALC, Mendonça AMS. 2014. Plantas ornamentais em quintais urbanos de Rio Branco, Brasil. Boletim do Museu Paraense Emílio Goeldi, Ciências Humanas, $9(3): 797-813$.

Souza LF, Guarim Neto G. 2010. Plantas ornamentais e místicas - um estudo etnobotânico em comunidades ribeirinhas, Cuiabá, Mato Grosso, Brasil. Flovet, 1(2):1-12.

Sousa, VC e Lorenzi H. 2012. Botânica sistemática: guia ilustrado para identificação das famílias de Fanerógamas nativas e exóticas no Brasil, baseado na APG III. $3^{a}$.ed. Nova Odessa: Instituto Plantarum, $768 \mathrm{p}$.

Trotta J, Messias PA, Catojo AHP, Hayashida CT, Camargo C, Futemma C. 2012. Análise do conhecimento e uso popular de plantas de quintais urbanos no estado de São Paulo, Brasil. Revista de estudos ambientais, 
14(3):17-34.

Van Holthe JMO. 2003. Quintais urbanos de Salvador: realidades, usos e vivências no século XIX. Cadernos, 2: 61-74.

Vendruscolo GS, Mentz LA. 2006. Levantamento etnobotânico das plantas utilizadas como medicinais por moradores do bairro Ponta Grossa, Porto Alegre, Rio Grande do Sul, Brasil. Iheringia, série Botânica, 61(12):83-103. 